\title{
Novos registros de algas verdes cocoides (Chlorophyceae, Chlorophyta) para o estado da Bahia e para o Brasil
}

\author{
Geraldo José Peixoto Ramos ${ }^{1 *}$, Carlos Eduardo de Mattos Bicudo ${ }^{2, a}$ \& Carlos Wallace do Nascimento \\ Moura $^{1, \mathrm{~b}}$ \\ ${ }^{1}$ Programa de Pós-graduação em Botânica, Departamento de Ciências Biológicas, Universidade Estadual de Feira \\ de Santana, Bahia, Brasil. \\ ${ }^{2}$ Núcleo de Pesquisa em Ecologia, Instituto de Botânica, São Paulo, Brasil.
}

\begin{abstract}
Resumo - A partir de coletas na Área de Proteção Ambiental Marimbus-Iraquara, Chapada Diamantina, Bahia, foram identificados 23 táxons de algas verdes cocoides. Dentre eles, 19 são novas ocorrências para a Bahia e quatro são novos registros para o Brasil: Coenocystis planctonica var. planctonica, C. planctonica var. hercynica, Dispora crucigenioides e Palmodictyon lobatum. Este é o primeiro registro confirmado do gênero Palmodictyon para o território brasileiro.

Palavras-chave adicionais: Caatinga, Chlorococcales, Sphaeropleales, taxonomia.
\end{abstract}

\begin{abstract}
New records of coccoid green algae (Chlorophyta, Chlorophyta) for the Bahia state and for Brazil) - Twenty-three taxa of coccoid green algae were identified from samples collected in the Marimbus-Iraquara Environmental Protection Area, Chapada Diamantina, Bahia state. Amongst them, 19 are reported for the first time to Bahia state and four are new reports to Brazil: Coenocystis planctonica var. planctonica, C. planctonica var. hercynica, Palmodictyon lobatum and Dispora crucigenioides. This is the first confirmed record of the genus Palmodictyon to the Brazilian territory.

Additional key words: Caatinga, Chlorococcales, Sphaeropleales, taxonomy.
\end{abstract}

As algas verdes cocoides, tradicionalmente conhecidas como Chlorococcales s.l., abrangem organismos unicelulares com ampla diversidade morfológica, habitando diversos ambientes aquáticos, com diferentes graus de trofia (Komárek \& Fott 1983; Comas 1996; Tsarenko \& John 2011). Estudos morfológicos, ultraestruturais e, principalmente, moleculares têm contribuído para a sistemática do grupo, que tem sido atualizada constantemente, provocando mudanças taxonômicas significativas (John et al. 2011; Krienitz \& Bock 2012; Bock et al. 2013).

Krienitz \& Bock (2012) realizaram uma revisão para as algas verdes cocoides (sensu Lewis \& McCourt 2004) e consideraram três classes: Trebouxiophyceae, Prasinophyceae e Chlorophyceae, sendo que a maioria dos membros desta última classe está inserida na ordem Sphaeropleales. No intuito de ampliar o conhecimento sobre a diversidade das algas verdes cocoides, pesquisas foram desenvolvidas em algumas localidades do Brasil, especialmente nas Regiões Sudeste (Fernandes \& Bicudo 2009; Godinho et al. 2010; Rosini et al. 2012, 2013), Sul (Moresco \& Bueno 2007; Bortolini et al. 2010a; Torgan \& Hentschke 2011; Domingues \& Torgan 2012; Hentschke \& Prado 2012) e Centro-Oeste (Nogueira \& Oliveira 2009; Bortolini et al. 2010b; Souza et al. 2014), sendo notória a escassez de estudos específicos desse grupo de algas nas Regiões Norte e Nordeste.

\footnotetext{
*Autor para correspondência: geraldojpr@gmail.com;

acbicudo@terra.com.br; ${ }^{b}$ wallace@uefs.br

Editor responsável: Alessandro Rapini

Submetido em: 28 jul. 2014; aceito em: 8 jan. 2015

Publicação eletrônica: 28 jan. 2015; versão final: 2 fev. 2015
}

Ainda são poucos os estudos sobre algas verdes cocoides no estado da Bahia (Martins et al. 1991; Fuentes et al. 2010; Severiano et al. 2012; Mendes et al. 2012a,b; Ramos et al. 2012) e o estudo mais recente registrou 11 novas ocorrências dessas algas para o Brasil e uma nova ocorrência para a região neotropical (Ramos et al. 2014). Assim, o presente trabalho teve como objetivos descrever, ilustrar e comentar os táxons de algas verdes cocoides de duas áreas do Pantanal dos Marimbus, Chapada Diamantina, os quais são novos registros para a Bahia e para o Brasil.

\section{MATERIAL E MÉTODOS}

O Pantanal dos Marimbus está localizado na porção leste do Parque Nacional da Chapada Diamantina, estado da Bahia. Envolve uma extensa área plana e pantanosa sujeita a inundações periódicas pelos rios e afluentes da região, como os rios Ribeirão, Capivara, Roncador, Caldeirão e Garapa. O Pantanal faz parte do complexo vegetacional da Chapada Diamantina, uma ecorregião bem delimitada dentro do bioma Caatinga. Os Marimbus são subdivididos em quatro áreas: Marimbus do Remanso (localizado ao norte, no Município de Lençóis), Marimbus da Fazenda Velha, Marimbus do Ferreira e Marimbus do Baiano (ao sul, no Município de Andaraí), todas interligadas pelo rio Santo Antônio (Figura 1). Nossas amostras foram coletadas de modo aleatório no Marimbus do Baiano e do Remanso (12 $\left.32^{\prime} 13^{\prime \prime}-12^{\circ} 46^{\prime} 48^{\prime \prime} \mathrm{S}, 41^{\circ} 17^{\prime} 00^{\prime \prime}-41^{\circ} 21^{\prime} 25^{\prime \prime} \mathrm{W}\right)$, durante o período seco (abril, junho e agosto de 2011) e o chuvoso (outubro e dezembro de 2011 e fevereiro de 2012). 


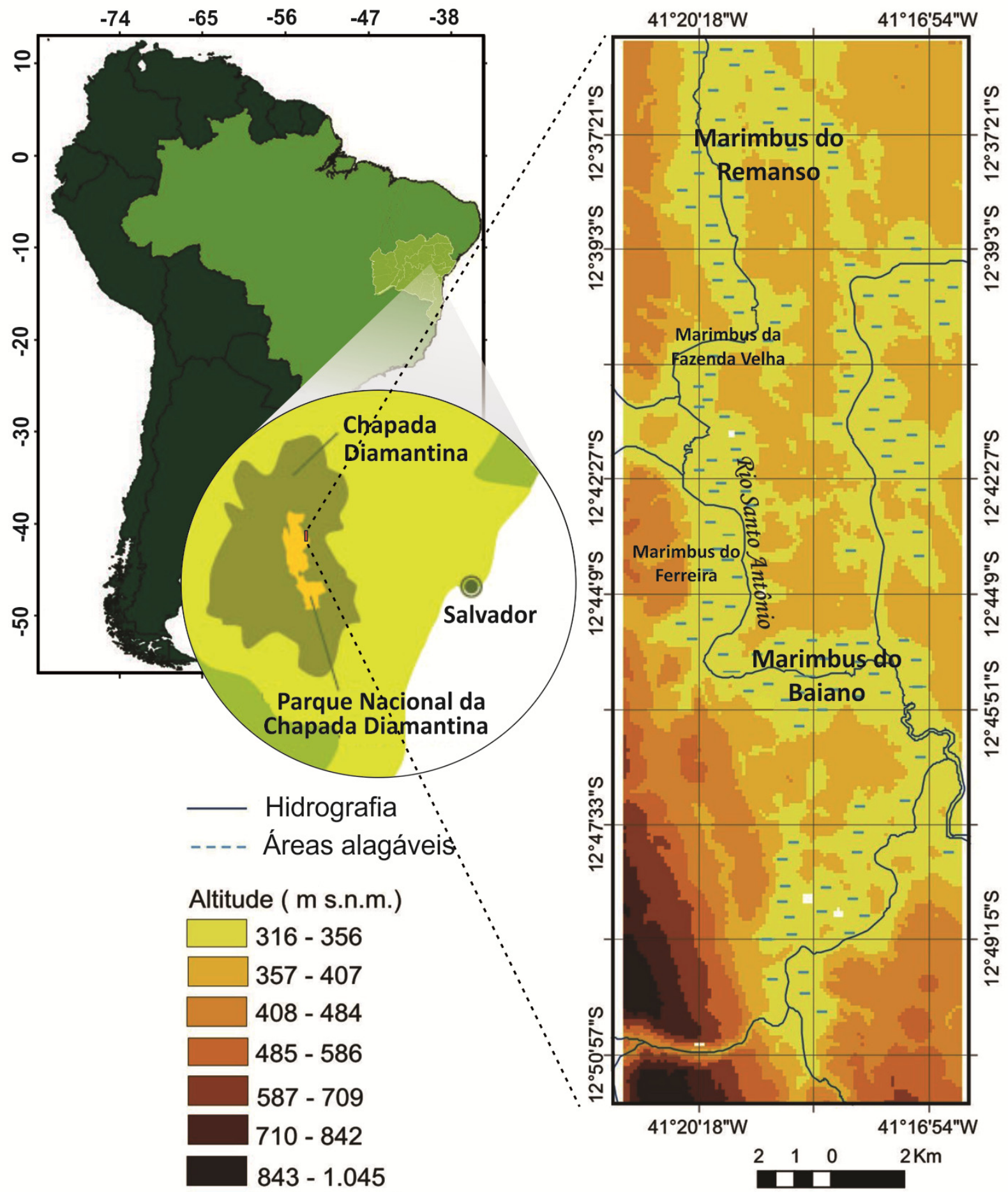

Figura 1. Mapa do Pantanal dos Marimbus, Chapada Diamantina, Bahia, Brasil (modificado de Ramos et al. 2014).

O Marimbus do Baiano é formado por várias lagoas interligadas, como a Lagoa do Baiano, Lagoa da Isca, Lagoa dos Paus, além do Olho D'água do Peri. As coletas no Marimbus do Baiano foram concentradas na Lagoa do Baiano, caracterizada por águas bastante calmas, escuras, com $\mathrm{pH}$ de 6,0 a 7,2 e transparência média da coluna da água de $0,90 \mathrm{~m}(0,4-1,8 \mathrm{~m})$. Além disso, existem diversas macrófitas aquáticas, dentre as quais destacam-se Utricularia foliosa L., Cabomba haynesii Wiersema, Eichhornia azurea (Sw.) Kunth e Nymphaea ampla (Salisb.) DC.

O Marimbus do Remanso é caracterizado por apresentar águas calmas (na maior parte dos trechos), escuras, com pH de 6,6 a 7,6 e transparência média da coluna da água de 2,1 m $(0,4-3,1 \mathrm{~m})$. É notável a influência do rio Santo Antônio na dinâmica do ambiente, principalmente nos trechos mais estreitos em que o fluxo da corrente é maior. Assim como no 
Marimbus do Baiano, a área é caracterizada por apresentar um grande número de macrófitas, principalmente Eichhornia azurea, Cabomba haynesii e Salvinia auriculata Aubl., bancos de Chara sp., além de densos filamentos de Spirogyra sp.

As coletas foram realizadas utilizando técnicas para o estudo taxonômico de algas de águas continentais (Bicudo \& Menezes 2006): para a amostragem de material planctônico, foi utilizada uma rede de plâncton de malha $20 \mu \mathrm{m}$, e para a amostragem de material perifítico, foi realizado um espremido manual em macrófitas aquáticas e partes de plantas submersas. As medidas dos táxons foram obtidas com uma ocular micrométrica e as fotografias com câmera digital acoplada ao microscópio óptico. O sistema de classificação adotado foi o de John et al. (2011). As amostras foram preservadas em solução de Transeau (Bicudo \& Menezes 2006) e depositadas na coleção liquida do Herbário da Universidade Estadual de Feira de Santana (HUEFS).

\section{RESULTADOS}

A partir do levantamento florístico das algas verdes cocoides nas duas áreas do Pantanal dos Marimbus (Baiano e Remanso), foram identificados 19 táxons que são novos registros para o estado da Bahia e quatro para o Brasil.

\section{Chlorococcales 'sensu stricto'}

\section{Apodochloris simplicissima (Koršikov) Komárek,} Preslia 31: 318; fig. 1. 1959.

Figura 2.

Célula solitária, piriforme, assimétrica, às vezes curvada; parede celular lisa; cloroplastídio 1, parietal, 1 pirenoide. Célula 15-21,2 $\mu \mathrm{m}$ compr., 7,5-8,8 $\mu \mathrm{m}$ larg.

Material examinado - BRASIL. BAHIA: Andaraí, Marimbus do Baiano, 29 jun. 2011, C.A. Ribeiro \& G.J.P. Ramos s.n. (HUEFS 178372); ib., 19 ago. 2011, C.W.N. Moura \& G.J.P. Ramos s.n. (HUEFS 185355); Lençóis, Marimbus do Remanso, 30 jun. 2011, C.A. Ribeiro \& G.J.P. Ramos s.n. (HUEFS 178380).

Distribuição geográfica no Brasil. Rio de Janeiro (Nogueira 1991), São Paulo (Fernandes 2008); primeira citação para o estado da Bahia.

De acordo com Fernandes (2008), A. simplicissima é próxima de $A$. polymorpha (Bischoff \& Bold) Komárek, que entretanto difere pelas dimensões maiores, 25-35(-50) $\mu \mathrm{m}$ compr. Nogueira (1991) também relatou a semelhança entre essas duas espécies, diferenciando-as pela morfologia dos zoósporos, elipsoides em A. simplicissima e ovoides em $A$. polymorpha. Embora os zoósporos não tenham sido observados, os exemplares estudados aqui são bastante semelhantes aos referidos por Nogueira (1991) e Fernandes (2008).
Sphaerocystis planctonica (Koršikov) Bourrelly, Preslia 46: 9. 1974.

Figuras 3 e 4.

Colônia arredondada, formada por 4,8 ou 16 células irregularmente dispostas em uma bainha de mucilagem firme e conspícua; células esféricas; cloroplastídio 1, poculiforme, 1 pirenoide. Reprodução por 4 ou 8 autósporos esféricos, liberados a partir da dissolução da parede da célula-mãe. Colônia 60-78 $\mu \mathrm{m}$ diâm., célula 5-8,8 $\mu \mathrm{m}$ diâm., autósporo 2,5-3,7 $\mu \mathrm{m}$ diâm.

Material examinado - BRASIL. BAHIA: Andaraí, Marimbus do Baiano, 1 abr. 2011, C.W.N. Moura \& G.J.P. Ramos s.n. (HUEFS 178326); ib., 29 jun. 2011, C.A. Ribeiro \& G.J.P. Ramos s.n. (HUEFS 178379); Lençóis, Marimbus do Remanso, 27 out. 2011, C.A. Ribeiro \& G.J.P. Ramos s.n. (HUEFS 185367).

Distribuição geográfica no Brasil. Amazonas (Bittencourt-Oliveira 1993), Rio Grande do Sul (Torgan 1997), São Paulo (Fonseca et al. 2014); primeira citação para o estado da Bahia.

Sphaerocystis planctonica assemelha-se morfologicamente a $S$. schroeteri Chodat, que difere pelas dimensões celulares maiores (células 9-15 $\mu \mathrm{m}$, colônias 82.5-123 $\mu \mathrm{m}$ ) e por apresentar mais células por colônia (até 64). Picelli-Vicentim (1987) e Sant'Anna (1984) consideraram os atributos métricos propostos por Komárek \& Fott (1983) insuficientes para distinguir essas espécies e sugeriram a necessidade de estudos mais detalhados sobre os aspectos reprodutivos para uma identificação mais precisa. Assim, preferimos identificar este táxon como S. planctonica, até que estudos mais detalhados para essas espécies sejam realizados.

\section{Sphaeropleales 'sensu lato'}

Characiellopsis skujae (Fott) Komárek, Arch. Hydrobiol. Suppl. 56: 242. 1979.

Figuras 5 e 6.

Célula solitária aderida ao substrato por disco basal, alongada, obovoide, mais estreita para a base; parede celular espessa, ápice da célula com engrossamento em forma de anel; cloroplastídio 1, laminar, parietal, revestindo internamente quase toda a célula, 1 pirenoide. Célula 30-45 $\mu \mathrm{m}$ compr., 10-15 $\mu \mathrm{m}$ larg.

Material examinado - BRASIL. BAHIA: Andaraí, Marimbus do Baiano, 26 out. 2011, C.A. Ribeiro \& G.J.P. Ramos s.n. (HUEFS 178372); ib., 10 fev. 2012, C.A. Ribeiro \& G.J.P. Ramos s.n. (HUEFS 185415); Lençóis, Marimbus do Remanso, 20 ago. 2011, C.W.N. Moura \& G.J.P. Ramos s.n. (HUEFS 178364).

Distribuição geográfica no Brasil. Paraná (Algarte et al. 2006; Felisberto \& Rodrigues 2010); primeira citação para o estado da Bahia.

Characiellopsis skujae tem como característica diagnóstica a presença de um espessamento apical da parede celular em forma de anel. Segundo Hindák \& Hindáková (2008), a taxonomia desta espécie ainda não está clara, principalmente em relação às 
características do cloroplastídio, as quais não foram retratadas de forma precisa em sua descrição original. A partir de observações de células jovens de Characium obtusum A.Braun (= Characiellopsis skujae), Skuja (1964) constatou a presença de cloroplastídio de forma estrelada, difícil de ser visualizada na fase adulta, uma vez que o plastídio recobre toda a cavidade celular. Nas populações do Pantanal dos Marimbus, não foram observados indivíduos com cloroplastídio estrelado, apenas laminar e parietal, revestindo internamente quase toda a célula, concordando com Komárek \& Fott (1983) e Hindák \& Hindáková (2008).

Characium ornithocephalum A.Braun, Alg. unicell.: 42; pl. 3-C. 1855.

Figura 7.

Indivíduo fixo, curto-pediculado, aderido perpendicularmente ou obliquamente ao substrato, pedículo filiforme; célula fusiforme, levemente assimétrica, margens uniformemente convexas, ápice acuminado, extremidade pontiaguda; parede celular lisa; cloroplastídio 1, laminar, parietal, revestindo internamente quase toda a célula, 1 pirenoide. Célula 16-17,5 $\mu \mathrm{m}$ compr., 6-8,5 $\mu \mathrm{m}$ larg., pedículo 6-70 $\mu \mathrm{m}$ compr.

Material examinado - BRASIL. BAHIA: Lençóis, Marimbus do Remanso, 20 ago. 2011, C.W.N. Moura \& G.J.P. Ramos s.n. (HUEFS 178364); ib., 11 fev. 2012, C.A. Ribeiro \& G.J.P. Ramos s.n. (HUEFS 185420).

Distribuição geográfica no Brasil. Mato Grosso do Sul, São Paulo, Paraná (Bueno et al. 2014); primeira citação para o estado da Bahia.

Segundo Fernandes (2008), o pedículo dessa espécie é bastante variável, podendo ser filiforme, grosseiro, reto ou irregular. Seu comprimento equivale, geralmente, a um terço ou metade do comprimento total da célula, mas também pode ser tão longo quanto ou pouco mais longo que a célula. Os pedículos das populações de $C$. ornithocephalum dos Marimbus apresentaram comprimento equivalente a um terço do comprimento total da célula, inseridos tanto perpendicular quanto obliquamente na célula, sendo este último mais comum no material analisado. Segundo Tsarenko \& John (2011), é uma espécie provavelmente cosmopolita, encontrada geralmente como epífita de clorofíceas filamentosas. No Pantanal dos Marimbus, foi registrada epifitando diatomáceas e, às vezes, zygnematofíceas filamentosas.

Characium rostratum Reinhard ex Printz, Kristiania 1913(6): 41. 1914.

Figura 8.

Indivíduo fixo, médio a longo-pediculado, aderido perpendicularmente ao substrato, pedículo filiforme, às vezes com disco de fixação; célula fusiforme a falciforme, margens ligeiramente convexas, ápice agudo, levemente curvo; parede celular lisa; cloroplastídio 1, laminar, parietal, revestindo internamente quase toda a célula, 1 pirenoide. Célula 20-28 $\mu \mathrm{m}$ compr., 5-6,5 $\mu \mathrm{m}$ larg., pedículo 16,2-18,5 $\mu \mathrm{m}$ compr.

Material examinado - BRASIL. BAHIA: Andaraí, Marimbus do Baiano, 19 ago. 2011, C.W.N. Moura \& G.J.P. Ramos s.n. (HUEFS 185350); ib., 9 dez. 2011, C.A. Ribeiro \& G.J.P. Ramos s.n. (HUEFS 185396); Lençóis, Marimbus do Remanso, 20 ago. 2011, C.W.N. Moura \& G.J.P. Ramos s.n. (HUEFS 185367).

Distribuição geográfica no Brasil. Rio de Janeiro, São Paulo (Bueno et al. 2014); primeira citação para o estado da Bahia.

De acordo com Nogueira (1991), C. rostratum e $C$. ornithocephalum são próximas devido à forma de fuso da célula, mas $C$. ornithocephalum apresenta células mais estreitas e curvadas. Os exemplares analisados por Nogueira (1991) apresentaram pedículos mais curtos $(8,9-15 \mu \mathrm{m})$ que os encontrados nos Marimbus. Komárek \& Fott (1983) consideraram o comprimento dos pedículos o principal critério de separação entre as espécies. $\mathrm{Na}$ área de estudo, C. rostratum apresentou pedículos longos e células de fusiforme a falciforme, enquanto $C$. ornithocephalum apresentou pedículos curtos e célula fusiforme. No Pantanal dos Marimbus, C. rostratum ocorreu de modo solitário, epifitando diatomáceas e clorofíceas filamentosas.

Coenococcus planctonicus Koršikov, Protococcineae: 322; fig. 295. 1953.

Figuras 9 e 10.

Colônia esférica ou irregular formada por grupos de 4,8 ou 16 células dispostas 2 a 2, em planos distintos, células de um dos planos localizadas irregularmente sobre as células do outro plano, raro tetraédricas, inseridas em uma bainha de mucilagem hialina; células esféricas; cloroplastídio 1, parietal, 1 pirenoide. Reprodução por 4 autósporos esféricos, dispostos tetraedricamente, liberados pela dissolução da parede da célula-mãe. Colônia 45-60 $\mu \mathrm{m}$ diâm, célula adulta 7,5-10 $\mu \mathrm{m}$ diâm, autósporo 5-7,5 $\mu \mathrm{m}$ diâm.

Material examinado - BRASIL. BAHIA: Andaraí, Marimbus do Baiano, 1 abr. 2011, C.W.N. Moura \& G.J.P. Ramos s.n. (HUEFS178332); ib., 29 jun. 2011, C.A. Ribeiro \& G.J.P. Ramos s.n. (HUEFS 178362); Lençóis, Marimbus do Remanso, 30 jun. 2011, C.A. Ribeiro \& G.J.P. Ramos s.n. (HUEFS 178380).

Distribuição geográfica no Brasil. Distrito Federal, Goiás, São Paulo, Rio de Janeiro e Paraná (Tucci et al. 2014a), além de Mato Grosso (De-Lamonica-Freire \& Sant'Anna 1993) (como Eutetramorus planctonicus); primeira citação para o estado da Bahia.

Morfologicamente, Coenococcus planctonicus lembra Coenochloris fotti, porém este último táxon difere do primeiro pelo arranjo de suas células, geralmente dispostas na configuração de uma coroa. Segundo Hindák (1988), as colônias de C. planctonicus podem apresentar dois padrões de arranjo: grupos de quatro células tetraedricamente dispostas ou grupos de duas células adjacentes, que se afastam entre si, porém, sempre se mantendo aos pares. Durante a análise das populações dos Marimbus, foi possível observar ambos 
os padrões, sendo o último mais comum que o primeiro.

Coenocystis planctonica Koršikov var. planctonica, Protococcineae: 328; fig. 302. 1953.

Figura 11.

Colônia esférica, 4 ou 8 células dispostas irregularmente no centro de uma bainha de mucilagem inconspícua; resquícios da parede da célula-mãe evidentes; células esféricas; parede celular lisa; cloroplastídio 1 , parietal, 1 pirenoide. Célula 10,5-15 $\mu \mathrm{m}$ diâm.

Material examinado - BRASIL. BAHIA: Andaraí, Marimbus do Baiano, 9 dez. 2011, C.A. Ribeiro \& G.J.P. Ramos s.n. (HUEFS 185388, HUEFS 185389, HUEFS 185391).

Distribuição geográfica no Brasil. Primeiro registro da espécie no Brasil.

Coenocystis planctonica var. planctonica é morfologicamente semelhante a Radiococcus planctonicus J.W.G.Lund, que difere por apresentar colônias com até 16 células e estrias radiadas na periferia da bainha de mucilagem, além de dimensões celulares menores. Segundo Komárek (1983), a principal característica para separar Coenocystis de Radiococcus é o arranjo paralelo dos autósporos no interior da célula-mãe, presente no primeiro gênero.

Coenocystis planctonica Koršikov var. hercynica (H.Heynig) Fott, Preslia 46: 19. 1974.

Figura 12.

Colônia arredondada, 8 células dispostas em dois planos distintos, localizadas no centro de bainha de mucilagem inconspícua; células elípticas a ovoides, parede celular lisa; cloroplastídio 1, parietal, 1 pirenoide. Célula 6,5-10 $\mu \mathrm{m}$ compr., 5-6 $\mu \mathrm{m}$ larg.

Material examinado - BRASIL. BAHIA: Andaraí, Marimbus do Baiano, 9 dez. 2011, C.A. Ribeiro \& G.J.P. Ramos s.n. (HUEFS 185388).

Distribuição geográfica no Brasil. Primeiro registro para o Brasil.

Segundo Komárek \& Fott (1983), C. planctonica var. hercynica difere da variedade típica pela presença de células elipsoides a ovoides, regularmente distribuídas no interior de uma bainha de mucilagem. Nas populações de Marimbus, não foram analisados restos da parede da célula-mãe na bainha de mucilagem, geralmente evidentes na variedade típica. Além disso, as células foram visualizadas em dois planos, caracterizando o arranjo em coroa, conforme ilustrações apresentadas por Komárek \& Fott (1983: pl. 123, fig. 3d-f). A disposição das células formando uma coroa em $C$. planctonica var. hercynica faz com que esta variedade seja semelhante a Coenochloris fottii (Hindák) P.M.Tsarenko, a qual difere dela por apresentar células esféricas e arranjo tetraédrico dos autósporos.
Coenocystis subcylindrica Koršikov, Protococcineae: 330; fig. 303. 1953.

Figuras 13 e 14.

Colônia arredondada, 4, 8, 16(32) células, células adultas dispostas irregularmente, porém, em 1 ou 2 planos na bainha de mucilagem conspícua; células oblongas a elipsoides; cloroplastídio 1, parietal, 1 pirenoide. Célula 7-12,5 $\mu \mathrm{m}$ compr., 3,8-6,2 $\mu \mathrm{m}$ larg.

Material examinado - BRAZIL. BAHIA: Andaraí, Marimbus do Baiano, 1 abr. 2011, C.W.N. Moura \& G.J.P. Ramos s.n. (HUEFS 178344); ib. 29 jun. 2011, C.A. Ribeiro \& G.J.P. Ramos s.n. (HUEFS 178366); Lençóis, Marimbus do Remanso, 11 fev. 2012, C.A. Ribeiro \& G.J.P. Ramos s.n. (HUEFS 185418).

Distribuição geográfica no Brasil. Amazonas, Minas Gerais, Paraná, Rio de Janeiro (Nogueira 1996), Roraima, Rio Grande do Norte (Tucci et al. 2014b), São Paulo (Rosini et al. 2012), Mato Grosso do Sul (Bortolini et al. 2010b); primeira citação para o estado da Bahia.

De acordo com Nogueira (1991), C. subcylindrica é morfologicamente similar a Radiococcus subcylindricus Koršikov, que difere por apresentar uma ampla bainha de mucilagem estruturada e as células adultas dispostas em arranjo paralelo e sem pirenoide.

Gloeocystis vesiculosa Nägeli, Gatt. Einzell. Alg.: 66; pl. 4. 1849.

Figura 15.

Colônia formada por 4 ou 8 células envoltas por bainhas concêntricas de mucilagem inseridas em uma bainha maior, de forma indefinida; células ovoides a globosas, às vezes assimétricas; cloroplastídio 1, parietal, poculiforme, 1 pirenoide. Célula 10-12 $\mu \mathrm{m}$ diâm.

Material examinado - BRASIL. BAHIA: Andaraí, Marimbus do Baiano, 29 jun. 2011, C.A. Ribeiro \& G.J.P. Ramos s.n. (HUEFS 178374); ib., 19 ago. 2011, C.W.N. Moura \& G.J.P. Ramos s.n. (HUEFS185349); Lençóis, Marimbus do Remanso, 20 ago. 2011, C.W.N. Moura \& G.J.P. Ramos s.n. (HUEFS 185365).

Distribuição geográfica no Brasil. Rio de Janeiro (Bicudo \& Bicudo 1969); primeira citação para o estado da Bahia.

Morfologicamente, Gloeocystis vesiculosa se parece com G. polydermatica (Kützing) Hindák, diferindo por apresentar células elipsoides a ovoides e cloroplastídio alongado, em forma de tubo. Os espécimes do Pantanal dos Marimbus apresentaram as medidas do diâmetro intermediárias quando comparadas com aquelas da literatura e inferiores às registradas por Bicudo \& Bicudo (1969) para o Parque Nacional do Itatiaia, Rio de Janeiro (15-16,6 $\mu \mathrm{m})$ e superiores às de Komárek \& Fott (1983), que descreveram exemplares medindo de 6-8 $\mu \mathrm{m}$.

Kirchneriella dianae (Bohlin) Comas var. dianae, Acta Bot. Cubana 2: 4. 1980.

Figura 16.

Colônias irregulares, formadas por 12-64 células dispostas radialmente, faces convexas voltadas para 
fora do cenóbio, envoltas por mucilagem ampla, hialina, inconspícua; célula lunada, contorno subovado, incisão em forma de "U", ápices pontiagudos; cloroplastídio 1, parietal, 1 pirenoide. Célula 5-10 $\mu \mathrm{m}$ compr., 2,5-3,5 $\mu \mathrm{m}$ larg.

Material examinado - BRASIL. BAHIA: Andaraí, Marimbus do Baiano, 1 abr. 2011, C.W.N. Moura \& G.J.P. Ramos s.n. (HUEFS 178329); ib., 19 ago. 2011, C.W.N. Moura \& G.J.P. Ramos s.n. (HUEFS 185357); Lençóis, Marimbus do Remanso, 10 dez. 2011, C.A. Ribeiro \& G.J.P. Ramos s.n. (HUEFS 185402).

Distribuição geográfica no Brasil. Tocantins, Goiás, Espírito Santo, São Paulo, Rio de Janeiro, Paraná (Tucci et al. 2014a); primeira citação para o estado da Bahia.

Quanto à morfologia, $K$. dianae var. dianae lembra K. lunaris (Kirchner) Möbius, que difere por apresentar contorno celular circular e possuir cenóbio com até 16 células. Os exemplares coletados nos Marimbus apresentaram comprimentos celulares similares aos registrados por Comas (1996) para Cuba e as descrições e ilustrações concordam com Comas (1996) e Komárek \& Fott (1983). Assim, a identificação foi mantida neste tratamento, apesar das medidas celulares estarem um pouco menores que as descritas por Komárek \& Fott (1983), que relataram medidas de $12-20 \mu \mathrm{m}$ compr.

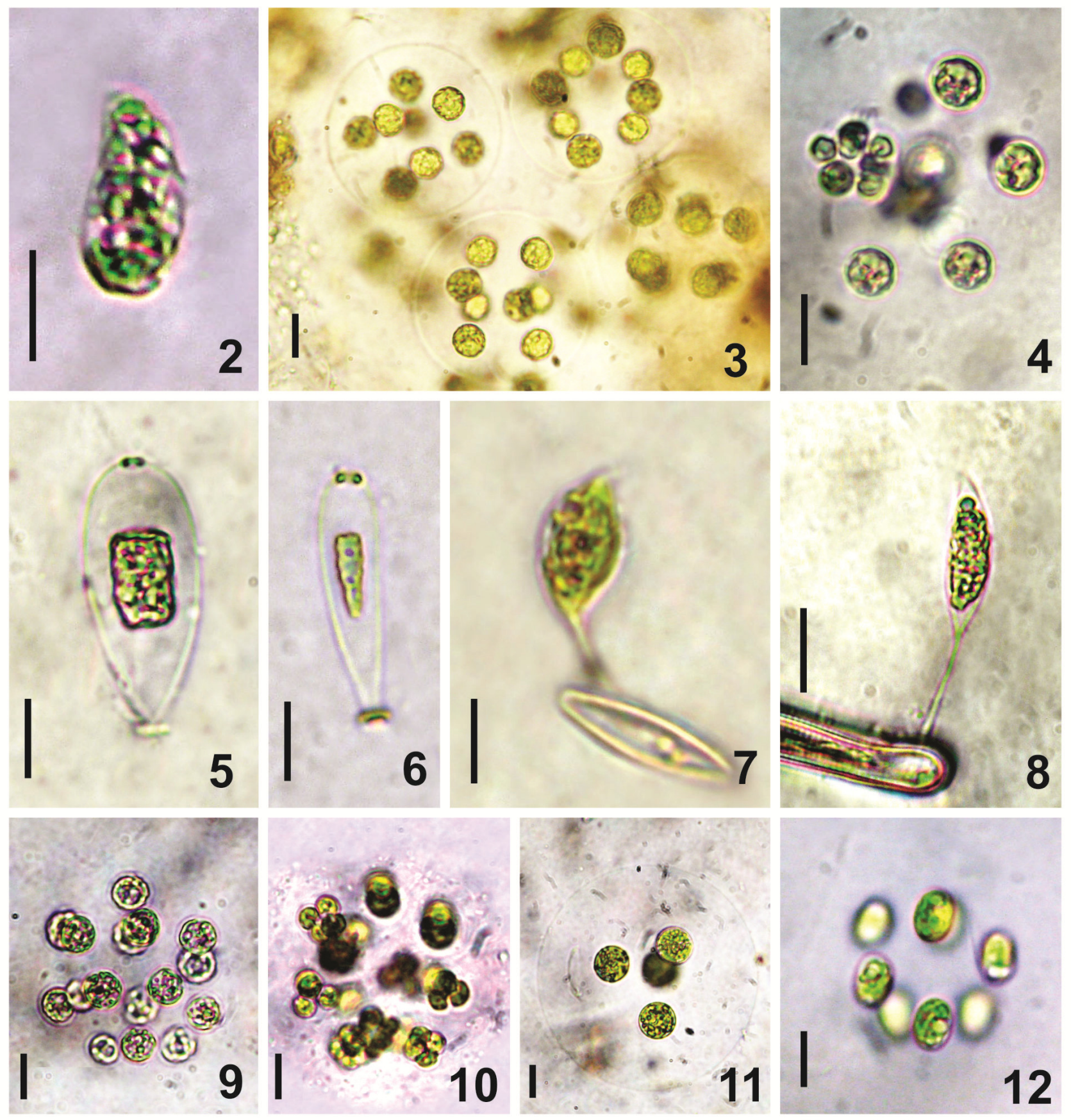

Figuras 2-12. Algas verdes cocoides, Pantanal do Marimbus, Bahia, Brasil: 2- Apodochloris simplicissima; 3, 4- Sphaerocystis planctonica; 5, 6- Characiellopsis skujae; 7- Characium ornithocephalum; 8- C. rostratum; 9, 10- Coenococcus planctonicus, mostrando colônia em autoesporulação (10); 11- Coenocystis planctonica var. planctonica; 12- C. planctonica var. hercynica. $($ Barra $=10 \mu \mathrm{m})$ 
Kirchneriella dianae (Bohlin) Comas var. major (Koršikov) Comas, Acta Bot. Cubana 2: 6. 1980. Figura 17.

Colônias irregulares, formadas por 12-32 células, faces convexas voltadas para fora do cenóbio, dispostas em mucilagem hialina, inconspícua; célula lunada, contorno subovado, incisão mediana em forma de "U", ápices levemente pontiagudos, uma extremidade mais alongada que a outra; cloroplastídio 1, parietal, 1 pirenoide. Célula 12,5-15 $\mu \mathrm{m}$ compr., 6,5-7,5 $\mu \mathrm{m}$ larg.

Material examinado - BRASIL. BAHIA: Andaraí, Marimbus do Baiano, 29 jun. 2011, C.A. Ribeiro \& G.J.P. Ramos s.n. (HUEFS 178362); ib., 19 ago. 2011, C.W.N. Moura \& G.J.P. Ramos s.n. (HUEFS 185348); Lençóis, Marimbus do Remanso, 20 ago. 2011, C.W.N. Moura \& G.J.P. Ramos s.n. (HUEFS 185365).

Distribuição geográfica no Brasil: Mato Grosso (De-Lamonica-Freire \& Sant'Anna 1993), Espírito Santo, São Paulo, Rio de Janeiro, Paraná (Tucci et al. 2014a); primeira citação para o estado da Bahia.

Kirchneriella dianae var. major difere da variedade típica por apresentar dimensões celulares maiores, ápices celulares levemente afilados, porém, uma das extremidades mais alongada que a outra. Esta variedade é comumente confundida com Kirchneriella lunaris, que tem o contorno celular aproximadamente circular, no entanto.

Kirchneriella irregularis (G.M.Smith) Koršikov, Protococcineae: 319; fig. 291. 1953.

Figura 18.

Colônias irregulares, formadas por 4-16 células dispostas irregularmente em mucilagem inconspícua, hialina; célula lunada, fusiforme, sigmoide; ápices arredondados ou levemente afilados; cloroplastídio 1, parietal, pirenoide não observado. Célula $6,2-8,7 \mu \mathrm{m}$ compr., 2,5-3,5 $\mu \mathrm{m}$ larg.

Material examinado - BRASIL. BAHIA: Lençóis, Marimbus do Remanso, 27 out. 2011, C.A. Ribeiro \& G.J.P. Ramos s.n. (HUEFS 185381); ib., 10 dez. 2011, C.A. Ribeiro \& G.J.P. Ramos s.n. (HUEFS 185398); ib., 11 fev. 2012, C.A. Ribeiro \& G.J.P. Ramos s.n. (HUEFS 185418).

Distribuição geográfica no Brasil. São Paulo (Tucci et al. 2006), Rio Grande do Sul (Domingues \& Torgan 2012), Goiás (Nogueira \& Oliveira 2009); primeira citação para o estado da Bahia.

Comas (1996) afirmou que $K$. irregularis possui um pirenoide conspícuo, muito embora Smith (1920), Koršikov (1953) e Hindák (1988) não mencionem a presença de tal organela celular. Morfologicamente, Kirchneriella irregularis assemelha-se a $K$. dianae, que difere dela por apresentar células com polos afilados e contorno subovoide.

Lemmermannia komarekii (Hindák) C.Bock \& Krienitz, J. Phycol. 49(2): 337. 2013.

Figura 19.

Cenóbio plano, 4 células, células dispostas de modo cruciado, pequeno espaço intercelular, com ou sem envoltório mucilaginoso; células subtriangulares, margens externas levemente convexas, arredondadas; cloroplastídio 1, parietal, sem pirenoide. Célula 2,5-3,8 $\mu \mathrm{m}$ diâm.

Material examinado - BRASIL. BAHIA: Andaraí, Marimbus do Baiano, 1 abr. 2011, C.W.N. Moura \& G.J.P.Ramos s.n. (HUEFS 178326); ib., 19 ago. 2011, C.W.N.Moura \& G.J.P.Ramos s.n. (HUEFS 185357): Lençóis, Marimbus do Remanso, 11 fev. 2012, C.A. Ribeiro \& G.J.P. Ramos s.n. (HUEFS 185423).

Distribuição geográfica no Brasil. Goiás, Distrito Federal, São Paulo e Paraná (como Tetrastrum komarekii Hindák; Tucci et al. 2014b); primeira citação para o estado da Bahia

Recentemente, baseados em estudos morfológicos e moleculares de algas verdes crucigenioides, Bock et al. (2013) transferiram algumas espécies de Tetrastrum, como T. komarekii, para o gênero Lemmermania pois mostraram relações próximas com o clado de Botryococus Kützing (Trebouxiophyceae). Morfologicamente, L. komarekii se assemelha a $L$. triangularis (Chodat) C.Bock \& Krienitz, que difere dela por apresentar pirenoide.

Monoraphidium flexuosum Komárek, Preslia 46: 119; fig.2. 1974.

Figura 20.

Célula isolada, curvada, fortemente arqueada na região mediana, ápices gradualmente afilados; cloroplastídio 1, parietal, sem pirenoide. Célula 45-50 $\mu \mathrm{m}$ compr., 1,5-2,5 $\mu \mathrm{m}$ larg.

Material examinado - BRASIL. BAHIA: Andaraí, Marimbus do Baiano, 19 ago. 2011, C.W.N. Moura \& G.J.P. Ramos s.n. (HUEFS 185348); ib., 9 dez. 2011, C.A. Ribeiro \& G.J.P. Ramos s.n. (HUEFS 185390); Lençóis, Marimbus do Remanso, 20 ago. 2011, C.W.N. Moura \& G.J.P. Ramos s.n. (HUEFS 185365).

Distribuição geográfica no Brasil. Goiás (Nogueira 1999), Rio Grande do Sul (Torgan 1997); primeira citação para o estado da Bahia.

Morfologicamente, $M$. flexuosum lembra $M$. arcuatum (Koršikov) Hindák, da qual difere por apresentar a célula em forma de arco, com o contorno semicircular. Os indivíduos do Pantanal dos Marimbus apresentaram medidas celulares inferiores às referidas por Nogueira (1999), cujo único exemplar encontrado mediu $72 \mu \mathrm{m}$ compr. e $1,5 \mu \mathrm{m}$ larg., porém de pleno acordo com as medidas, descrição e ilustração apresentadas por Torgan (1997).

Monoraphidium intermedium Hindák, Biol. Práce 30(1): 217; pl. 79, fig. 1-4. 1984.

Figura 21.

Célula isolada, fusiforme, cilíndrica, reta, ápices abruptamente arredondados; cloroplastídio 1, parietal, sem pirenoide. Célula 28,5-38 $\mu \mathrm{m}$ compr., 1,8-2,5 $\mu \mathrm{m}$ larg.

Material examinado - BRASIL. BAHIA: Andaraí, Marimbus do Baiano, 19 ago. 2011, C.W.N. Moura \& G.J.P. Ramos s.n. (HUEFS 185356); ib., 26 dez. 2011, C.A. Ribeiro \& G.J.P. Ramos s.n. (HUEFS 185368); Lençóis, Marimbus do Remanso, 20 ago. 2011, C.W.N. Moura \& G.J.P. Ramos s.n. (HUEFS 185358). 
Distribuição geográfica no Brasil. Goiás (Nogueira 1999); primeira citação para o estado da Bahia.

Morfologicamente, $M$. intermedium é semelhante a M. griffithii (Berkeley) Komárková-Legnerová, que difere dela por apresentar dimensões celulares maiores e ápices proporcionalmente mais afilados. Os exemplares dos Marimbus concordaram com as medidas, descrições e ilustrações do material coletado por Nogueira (1999) no estado de Goiás e por Hindák (1988) na Eslováquia.

Palmodictyon lobatum Koršikov, Protococcineae: 211; fig. 152. 1953.

Figuras 22 e 23.

Colônia tubular, irregularmente ramificada; células esféricas a ovoides, dispostas em fileira, envoltas por 1 bainha de mucilagem tubular; cloroplastídio 1, parietal, poculiforme, 1 pirenoide. Célula 5-7,5 $\mu \mathrm{m}$ diâm, bainha de mucilagem 18,8-45 $\mu \mathrm{m}$ diâm.

Material examinado - BRASIL. BAHIA: Andaraí, Marimbus do Baiano, 1 abr. 2011, C.W.N. Moura \& G.J.P. Ramos s.n. (HUEFS 178326); ib., 19 ago. 2011, C.W.N. Moura \& G.J.P. Ramos s.n. (HUEFS 185355).

Distribuição geográfica no Brasil. Primeiro registro da espécie no Brasil.

Não há registros desse gênero no Brasil, embora Bicudo \& Menezes (2006) tenham relatado a coleta de $P$. viride Kütz. no Parque Estadual das Fontes do Ipiranga, São Paulo. Segundo Kostikov et al. (2002), a bainha de mucilagem tubular e ramificada de Palmodictyon é resultante da extensão da parede da célula-mãe, a qual se rompe perpendicularmente ao
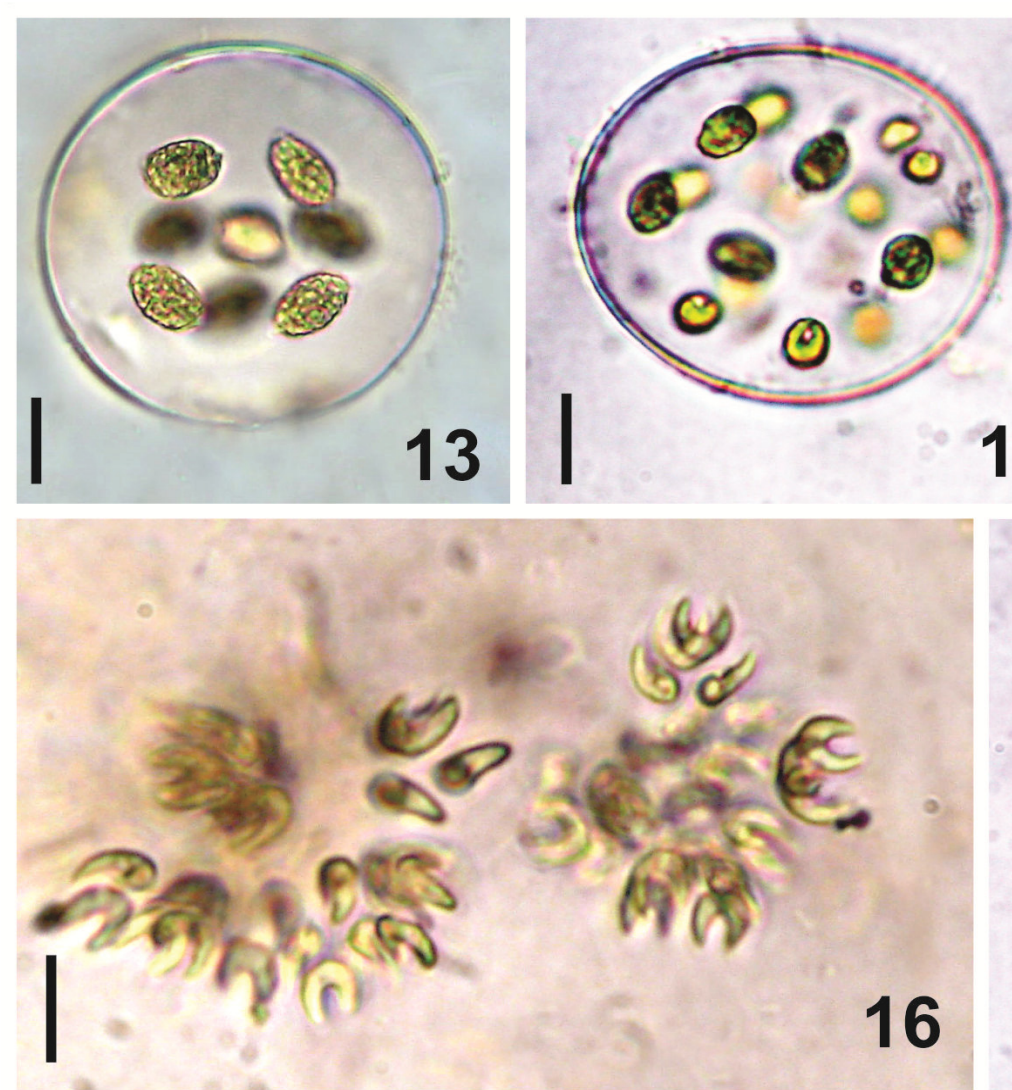

14
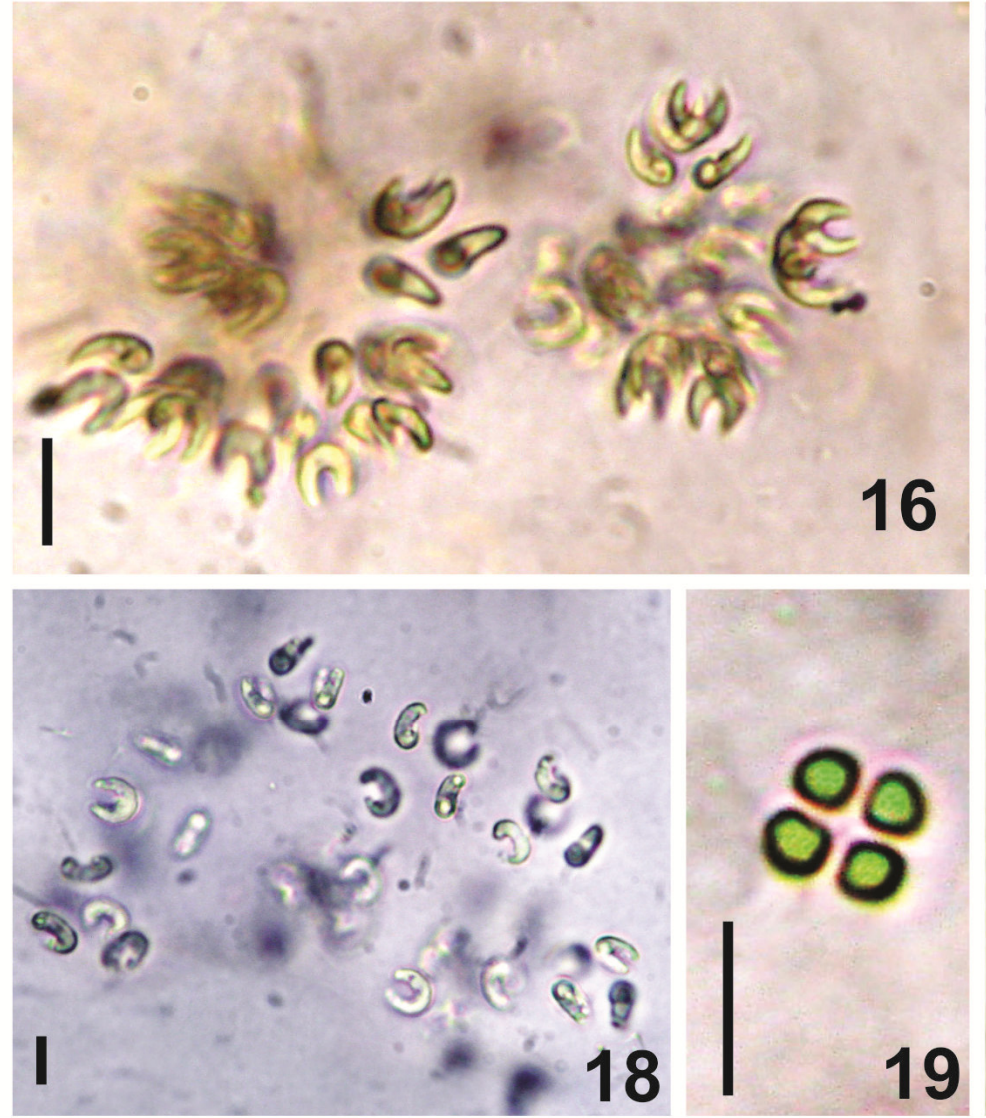

Figuras 13-21. Algas verdes cocoides, Pantanal do Marimbus, Bahia, Brasil: 13, 14- Coenocystis subcylindrica; 15- Gloeocystis vesiculosa; 16- Kirchneriella dianae var. dianae; 17- K. dianae var. major; 18- K. irregularis; 19- Lemmermannia komarekii; 20- Monoraphidium flexuosum; 21- M. intermedium. (Barra $=10 \mu \mathrm{m})$ 
eixo principal da bainha de mucilagem. Morfologicamente, $P$. lobatum lembra $P$. viride, que difere da primeira espécie por apresentar cloroplastídio reticulado destituído de pirenoide. Palmodictyon lobatum foi registrada apenas no Marimbus do Baiano, geralmente associada a folhas de Eichhornia azurea e a algumas Cyperaceae. Conforme relatado por Bicudo \& Menezes (2006), apesar de Palmodictyon ser comumente encontrado em vários locais do mundo, suas espécies dificilmente são coletadas em abundância. Durante nossos estudos, pouquíssimos exemplares da espécie foram encontrados.

Planktosphaeria gelatinosa G.M.Smith, Trans. Wis. Acad. Sc., Arts \& Lett. 19: 627; pl. 10, figs. 8-11. 1918.

Figura 24.

Célula solitária ou em colônia; célula esférica envolta por uma bainha mucilaginosa, homogênea, hialina; vários cloroplastídios, parietais, em forma de placas poligonais, 1 pirenoide por cloroplastidio. Célula 10-12 $\mu \mathrm{m}$ diâm.

Material examinado - BRASIL. BAHIA: Andaraí, Marimbus do Baiano, 1 abr. 2011, C.W.N. Moura \& G.J.P. Ramos s.n. (HUEFS 178344); ib., 10 fev. 2012, C.A. Ribeiro \& G.J.P.Ramos s.n. (HUEFS 185411); Lençóis, Marimbus do Remanso, 2 abr. 2011, C.W.N. Moura \& G.J.P. Ramos s.n. (HUEFS 185351).

Distribuição geográfica no Brasil. Amazonas (Sant'Anna \& Martins 1982), São Paulo (Sant'Anna 1984), Goiás (Nogueira 1999), Paraná (PicelliVicentim 1987); primeira citação para o estado da Bahia.

Planktosphaeria gelatinosa tem como características diagnósticas a bainha de mucilagem envolvendo a célula esférica e a presença de vários cloroplastídios parietais em forma de placas poligonais na fase adulta. Hindák (1984) comentou sobre a proximidade de Planktosphaeria com o gênero Sphaerocystis, que difere por apresentar células com apenas um cloroplastídio parietal.

Radiococcus planktonicus J.W.G.Lund, Bot. J. Linn. Soc. 55: 594. 1956.

Figuras 25 e 26.

Colônia arredondada formada por grupos de 4 células tetraedricamente dispostas em uma bainha de mucilagem hialina, geralmente com estrias na margem; células esféricas, às vezes com partes remanescentes da parede da célula-mãe (subcolônias); cloroplastídio 1, poculiforme, parietal, 1 pirenoide. Célula 6,3-7,5 $\mu \mathrm{m}$ diâm.

Material examinado - BRASIL. BAHIA: Andaraí, Marimbus do Baiano, 29 jun. 2011, C.A. Ribeiro \& G.J.P. Ramos s.n. (HUEFS 178362); ib., 19 ago. 2011, C.W.N. Moura \& G.J.P. Ramos s.n. (HUEFS 185348); Lençóis, Marimbus do Remanso, 30 jun. 2011, C.A. Ribeiro \& G.J.P. Ramos s.n. (HUEFS 178380).

Distribuição geográfica no Brasil. São Paulo (Sant'Anna 1984), Goiás (Nogueira \& Oliveira 2009),
Minas Gerais (Eterovick \& Giani 1997), Rio Grande do Sul (Hentschke \& Prado 2012); primeira citação para o estado da Bahia.

Nas populações estudadas, alguns espécimes apresentaram estrias radiais na margem da bainha de mucilagem, conforme relatado por Sant'Anna (1984) e Picelli-Vicentim (1987). De acordo com Pažoutová (2008), tais estrias poderiam ser formadas pela associação com bactérias. Outra característica variável nos espécimes analisados foram os restos da parede da célula-mãe, geralmente nas células jovens, concordando com Hindak (1988) e Tsarenko \& John (2011). Apesar dessas variações, os critérios para identificar o material como $R$. planktonicus foram a presença de células moderadamente afastadas umas das outras, dispostas em tetraedro e inseridas em uma bainha de mucilagem, cloroplastídio parietal poculiforme e dimensões celulares.

Raphidocelis contorta (Schmidle) Marvan, Komárek \& Comas, Algol. Stud. 37: 386, fig. 12. 1984.

Figura 27.

Colônia com 4, 8 ou 16 células dispostas irregularmente em 1 bainha gelatinosa, delgada; célula sigmoide, irregularmente helicoidal, polos arredondados; cloroplastídio 1, parietal, sem pirenoide. Célula 12,5-13,8 $\mu \mathrm{m}$ compr., 1,5-2 $\mu \mathrm{m}$ larg.

Material examinado - BRASIL. BAHIA: Andaraí, Marimbus do Baiano, 26 out. 2011, C.A. Ribeiro \& G.J.P. Ramos s.n. (HUEFS 185373); ib., 10 fev. 2012, C.A. Ribeiro \& G.J.P. Ramos s.n. (HUEFS 185415); Lençóis, Marimbus do Remanso, 20 ago. 2011, C.W.N. Moura \& G.J.P. Ramos s.n. (HUEFS 185367).

Distribuição geográfica no Brasil. Rio Grande do Sul (Domingues \& Torgan 2012), Goiás (Tucci et al. 2014a), São Paulo (Fonseca et al. 2014): primeira citação para o estado da Bahia.

De acordo com Krienitz \& Bock (2012), Kirchneriella e Raphidocelis são morfologicamente semelhantes. Entretanto, Kirchneriella apresenta células semilunadas a lunadas, formando colonias, enquanto Raphidocelis é caracterizado por apresentar células torcidas ou arqueadas, podendo viver de modo solitário ou formando colônias irregulares. Morfologicamente, Raphidocelis contorta, na fase unicelular, lembra Monoraphidium contortum (Thuret) Komárková-Legnerová, que difere dela por apresentar célula solitária, sem bainha de mucilagem e com polos afilados.

\section{Incertae sedis}

Komárek \& Fott (1983) e Comas (1996) posicionaram Dispora e Drepanochloris na ordem Chlorococcales 'sensu lato' (Chlorophyta). Entretanto, a ausência de estudos moleculares com esses gêneros tem impossibilitado o posicionamento preciso de suas espécies na Divisão Chlorophyta. 
Dispora crucigenioides Printz, Kristiania 1913(6): 32; pl. 1, fig. 13-15; pl. 2, fig. 16. 1914. Figura 28.

Colônia formada por 8 ou 16 células envoltas por uma bainha de mucilagem esférica, com uma leve incisão mediana; células globosas, organizadas aos pares ou em grupos de 4, bainha de mucilagem inconspícua envolvendo cada célula; cloroplastídio 1, parietal, sem pirenoide. Célula 7,5-10 $\mu \mathrm{m}$ diâm.

Material examinado - BRASIL. BAHIA: Andaraí, Marimbus do Baiano, 29 jun. 2011, C.A. Ribeiro \& G.J.P. Ramos s.n. (HUEFS 178372); ib., 26 out. 2011, C.A. Ribeiro \& G.J.P. Ramos s.n. (HUEFS 185371); ib., 10 fev. 2012, C.A. Ribeiro \& G.J.P. Ramos s.n. (HUEFS 185410).

Distribuição geográfica no Brasil. Primeiro registro da espécie no Brasil.

Dispora crucigenioides difere das demais espécies do gênero pela presença de uma inconspícua bainha de mucilagem ao redor de cada célula e pela leve incisão mediana da bainha colonial. Morfologicamente, $D$. crucigenioides se assemelha a D. speciosa Koršikov, que difere por não apresentar mucilagem individual, apenas a bainha colonial sem a incisão. Segundo Komárek \& Fott (1983), estas espécies são muito semelhantes, sendo às vezes difícil separá-las, pois a mucilagem individual é de difícil visualização. Nos nossos exemplares, foi possível observar tanto a bainha individual das células, quanto uma leve incisão mediana na bainha colonial, semelhante à ilustrada por Komárek \& Fott (1983: pl. 130, fig. 1a).

Drepanochloris nannoselene (Skuja) Marvan, Komárek \& Comas, Algol. Stud.37: 388. 1984. Figura 29

Célula solitária, lunada, afilada gradualmente para os ápices, polos levemente pontiagudos; parede celular lisa; cloroplastídio 1, parietal, 1 pirenoide. Célula 7,5$10 \mu \mathrm{m}$ compr., 2-3 $\mu \mathrm{m}$ larg.

Material examinado - BRASIL. BAHIA: Lençóis, Marimbus do Remanso, 20 ago. 2011, C.W.N. Moura \& G.J.P. Ramos s.n. (HUEFS 185364).

Distribuição geográfica no Brasil. Goiás (Nogueira 1999); primeira citação para o estado da Bahia.

De acordo com Comas (1996), Drepanochloris é morfologicamente intermediário aos gêneros Chlorolobion Koršikov e Monoraphidium KomárkováLegnerová. Difere do primeiro gênero por apresentar isopolaridade e ser de vida livre e do segundo por apresentar pirenoide. Morfologicamente, Drepanochloris nannoselene é similar a Monoraphidium subclavatum e Drepanochloris uherkovichii. Entretanto, a primeira espécie não apresenta pirenoide e a segunda apresenta células fortemente arqueadas e dimensões maiores.

Drepanochloris uherkovichii Marvan, Komárek \& Comas, Algol. Stud. 37: 388. 1984.

Figura 30.

Célula solitária, fortemente arqueada, afilada gradualmente para os ápices, polos pontiagudos; parede celular lisa, cloroplastídio 1, parietal, 1 pirenoide. Célula 16,5-18,8 $\mu \mathrm{m}$ compr., 2,5-3,5 $\mu \mathrm{m}$ larg.

Material examinado - BRASIL. BAHIA: Andará, Marimbus do Baiano, 19 ago. 2011, C.W.N. Moura \& G.J.P. Ramos s.n. (HUEFS185355); ib., 26 out. 2011, C.A. Ribeiro \& G.J.P. Ramos s.n. (HUEFS 185368); Lençóis, Marimbus do Remanso, 10 dez. 2011, C.A. Ribeiro \& G.J.P. Ramos s.n. (HUEFS 185400).

Distribuição geográfica no Brasil. Goiás (Nogueira 1999), São Paulo (Ferragut et al. 2005), Rio Grande do Sul (Torgan 1997); primeira citação para o estado da Bahia.

Morfologicamente, Drepanochloris uherkovichii se parece com Monoraphidium caribeum e Drepanochloris nannoselene, mas a primeira não apresenta pirenoide e a segunda apresenta células lunadas e dimensões menores. As medidas, descrições e ilustrações do material analisado aqui concordam com as referidas por Comas (1996) para o material de Cuba, Ferragut et al. (2005) para o de São Paulo e Nogueira (1999) para o de Goiás.

\section{CONSIDERAÇões FinaIS}

A partir deste estudo foi ampliada a distribuição geográfica de clorofíceas cocoides no Brasil. Dentre os táxons estudados, 19 são novos registros para a Bahia e quatro para o Brasil: Coenocystis planctonica var. planctonica, C. planctonica var. hercynica, Dispora crucigenioides e Palmodictyon lobatum

Ao comparar a ocorrência dos táxons nas duas áreas, observou-se que apenas Kirchneriella irregularis e Drepanochloris nannoselene tiveram ocorrência restrita ao Marimbus do Remanso, enquanto Coenocystis planctonica var. planctonica, C. planctonica var. hercynica, Dispora crucigenioides e Sphaerocystis planctonica foram encontrados exclusivamente no Marimbus do Baiano. Os demais táxons foram comuns às duas áreas estudadas.

Em relação ao hábitat, 15 clorofíceas estiveram presentes exclusivamente na comunidade perifítica e oito ocorreram tanto na perifítica quanto na planctônica. Nenhuma espécie ocorreu exclusivamente na comunidade planctônica. Supõese que esse predomínio de algas perifíticas deva estar relacionado às comunidades de macrófitas da área litorânea nas duas áreas do Pantanal dos Marimbus. Segundo Felisberto \& Murakami (2013), as macrófitas aumentam a área de superfície para colonização de algas e outros organismos e a senescência de suas folhas liberam nutrientes e compostos orgânicos dissolvidos que prontamente são utilizados pela microflora perifítica, principalmente em águas oligotróficas como as encontradas na região do Pantanal dos Marimbus. 


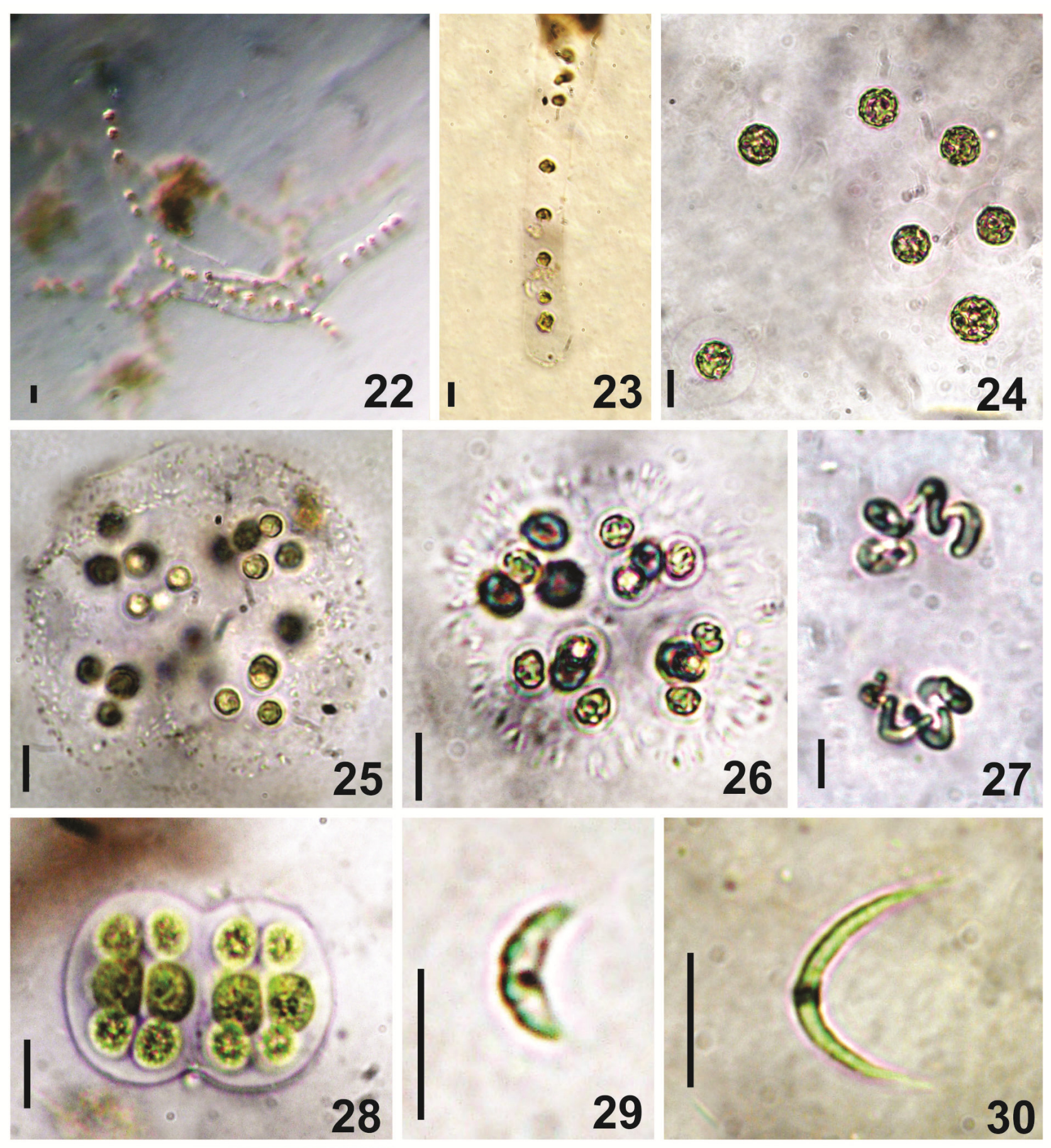

Figuras 22-30. Algas verdes cocoides, Pantanal do Marimbus, Bahia, Brasil: 22, 23- Palmodictyon lobatum; 24- Planktosphaeria gelatinosa; 25, 26- Radiococcus planktonicus; 27- Raphidocelis contorta; 28- Dispora crucigenioides; 29- Drepanochloris nannoselene; 30- D. uherkovichii. $($ Barra $=10 \mu \mathrm{m})$

\section{REFERÊNCIAS}

Algarte, V.M.; Moresco, C. \& Rodrigues, L. 2006. Algas do perifiton de distintos ambientes na planície de inundação do alto rio Paraná. Acta Scientiarum (Biological Sciences) 28: 243-251.

Bicudo, C.E.M. \& Bicudo, R.M.T. 1969. Algas da Lagoa das Prateleiras, Parque Nacional do Itatiaia, Brasil. Rickia 4: 1-40.

Bicudo, C.E.M. \& Menezes, M. 2006. Gêneros de Algas de Águas Continentais do Brasil: chave para identificação e descrições. 2 ed. RiMa, São Carlos.
Bittencourt-Oliveira, M.C. 1993. Ficoflórula do Reservatório de Balbina, Estado do Amazonas, 1: Chlorococcales (Chlorophyceae). Revista Brasileira de Biologia 53(1): 113129.

Bock, C.; Luo, W.; Kusber, W.-H.; Hegewald, E.; Pažoutová, M. \& Krienitz, L. 2013. Classification of crucigenoid algae: phylogenetic position of the reinstated genus Lemmermannia, Tetrastrum spp. Crucigenia tetrapedia, and C. lauterbornii (Trebouxiophyceae, Chlorophyta). Journal of Phycology 49: 329-339. 
Bortolini, J.C.; Meurer, T.; Godinho, L.R. \& Bueno, N.C. 2010a. Chlorococcales planctônicas do rio São João, Parque Nacional do Iguaçu, Paraná, Brasil. Hoehnea 37(2): 315-330.

Bortolini, J.C.; Biolo, S.; Bueno, N.C.; Godinho, L.R. \& Pott,V.J. 2010b. Chlorococcales sensu lato (Chlorophyceae) em tanques de depuração de efluente de origem bovina no Mato Grosso do Sul, Brasil. Iheringia série Botânica 65: 63-74.

Bueno, N.C.; Meurer, T. \& Bicudo, C.E.M. 2014. Charophyceae. In: Lista de Espécies da Flora do Brasil. Jardim Botânico do Rio de Janeiro. Disponível em http://floradobrasil.jbrj.gov.br/ jabot/floradobrasil/FB119894; acesso em 1 jul. 2014

Comas, A. 1996. Las Chlorococcales dulciacuícolas de Cuba. Biblioteca Phycologica 99: 1-265.

De-Lamonica-Freire, E.M. \& Sant'Anna, C.L. 1993. Chlorococcales (Chlorophyceae) da Estação Ecológica da Ilha de Taiamã, estado de Mato Grosso, Brasil. Hoehnea 20: 107-118.

Domingues, C.D. \& Torgan, L.C. 2012. Chlorophyta de um lago artificial hipereutrófico no sul do Brasil. Iheringia série Botânica 67(1): 75-91.

Eterovick, P.C. \& Giani, A. 1997. Levantamento taxonômico das Chlorophyta (Volvocales, Chlorococcales, Zygnematales) do Reservatório da Pampulha, MG. Revista Brasileira de Botânica 20: 79-90.

Felisberto, S.A. \& Rodrigues, L. 2010. Periphytic algal community in artificial and natural substratum in a tributary of the Rosana reservoir (Corvo Stream, Paraná State, Brazil). Acta Scientiarum (Biological Sciences) 32(4): 373-385.

Felisberto, S.A. \& Murakami, E.A. 2013. Papel do Perifiton na ciclagem de nutrientes e na teia trófica. In: A. Schwarzbold, A.L. Burliga \& L.C. Torgan, (eds), Ecologia do Perifiton. RiMa, São Carlos, p. 23-43.

Fernandes, S. 2008. As Famílias Chlorococcaceae e Coccomyxaceae no Estado de São Paulo: levantamento florístico. Tese de Doutorado. Universidade de São Paulo.

Fernandes, S. \& Bicudo, C.E.M. 2009. Criptógamos do Parque Estadual das Fontes do Ipiranga, São Paulo, SP. Algas, 25: Chlorophyceae (famílias Chlorococcaceae e Coccomyxaceae). Hoehnea 36(1): 173-191.

Ferragut, C.; Lopes, M.R.M.; Bicudo, D.C.; Bicudo, C.E.M. \& Vercellino, I.S. 2005. Ficoflórula perifítica e planctônica (exceto Bacillariophyceae) de um reservatório oligotrófico raso (Lago do IAG, São Paulo). Hoehnea 32(2): 137-184.

Fonseca, B.M.; Ferragut, C.; Tucci, A.; Crossetti, L.O.; Ferrari, F.; Bicudo, D.C.; Sant'Anna, C.L. \& Bicudo, C.E.M. 2014. Biovolume de cianobactérias e algas de reservatórios tropicais do Brasil com diferentes estados tróficos. Hoehnea 41(1): 9-30.

Fuentes, E.V.; Oliveira, H.S.B.; Cordeiro-Araújo, M.K.: Severi, W. \& Moura, A.N. 2010. Variação espacial e temporal do fitoplâncton do Rio de Contas, Bahia, Brasil. Revista Brasileira de Engenharia de Pesca 5(2): 13-25.

Godinho, L.R.; Comas, A. \& Bicudo, C.E.M. 2010. Criptógamos do Parque Estadual das Fontes do Ipiranga, São Paulo, SP. Algas, 30: Chlorophyceae (família Scenedesmaceae). Hoehnea 37: 513-553.

Hentschke, G.S. \& Prado, J.F. 2012. Chlorococcales s.l. (Chlorophyceae) e Zygnematales (Zygnematophyceae) em um açude do Balneário do Lérmen, Rio Grande do Sul, Brasil. Iheringia série Botânica 67(1): 59-74.
Hindák, F. 1984. Studies on the chlorococcal algae (Chlorophyceae), 3. Biologické Práce 30: 1-308.

Hindák, F. 1988. Studies on the chlorococcal algae (Chlorophyceae), 4. Biologické Práce 34: 1-263.

Hindák, F. \& Hindáková, A. 2008. Morphology and taxonomy of some rare chlorococcalean algae (Chlorophyta). Biologia 63(6): 781-790.

John, D.M.; Whitton, B.A. \& Brook, A.J. 2011. The Freshwater Algal Flora of the British Isles. An identification guide to freshwater and terrestrial algae. 2 ed. British Phycological Society and The Natural History Museum, London.

Komárek, J .1983. Contribution to the chlorococcal algae of Cuba. Nova Hedwigia 37: 65-180.

Komárek, J. \& Fott, B. 1983. Chlorophyceae (grünalgen) Ordnung: Chlorococcales. In: G. Huber-Pestalozzi (org.), Das Phytoplankton des Süsswassers: Systematic und Biologie. Vol. 7, part. 1. E. Schweizerbart'sche Verlagsbuchhandling (Nägele u. Obermiller), Stuttgart.

Koršikov, O.A. 1953. Pidklas Protokokovi (Protococcineae). Viznačnik prisnovodnich vodorostej Ukrainskoj RSR 5.

Kostikov, I.; Darienko, T.; Lukešová, A. \& Hoffmann, L. 2002: Revision of the classification system of Radiococcaceae Fott ex Komárek (except the subfamily Dictyochlorelloideae) (Chlorophyta). Algological Studies 104: 23-58.

Krienitz, L. \& Bock, C. 2012. Present state of the systematics of planktonic coccoid green algae of inland waters. Hydrobiologia 698(1): 295-326.

Lewis, L.A. \& McCourt, R.M. 2004. Green algae and the origin of land plants. American Journal of Botany 91:1535-1556.

Martins, D.V.; Sant'Anna, C.L. \& Oliveira, O.C. 1991. Estudo qualitativo do fitoplâncton do Dique do Tororó, Salvador, Bahia, Brasil. Revista Brasileira de Biologia 51(2): 445-453.

Mendes, M.C.Q.; Comas, A.; Moreno, M.L.V.; Figueira, C.P. \& Nunes, J.M.C. 2012a. Morphological and ultrastructural features of a strain of Botryococcus terribilis (Trebouxiophyceae) from Brazil. Journal of Phycology 48: 1099-1106.

Mendes, M.C.Q.; Comas, A.; Menezes, M.; Nunes, J.M.C.; Pereira, S. \& Nascimento, I.A. 2012b. Coleção de microalgas de ambientes dulciaquícolas naturais da Bahia, Brasil, como potencial fonte para a produção de biocombustíveis: uma abordagem taxonômica. Acta Botanica Brasilica 26(3): 691696.

Moresco, C. \& Bueno, N.C. 2007. Scenedesmaceae (Chlorophyceae, Chlorococcales) de um lago artificial urbano: Desmodesmus e Scenedesmus. Acta Scientiarum (Biological Sciences) 29: 289-296.

Nogueira, I.S. 1991. Chlorococcales Sensu Lato (Chlorophyceae) do Município do Rio de Janeiro e Arredores, Brasil: inventário $e$ considerações taxonômicas. Dissertação de Mestrado. Universidade Federal do Rio de Janeiro.

Nogueira, I.S. 1999. Estrutura e Dinâmica da Comunidade Fitoplanctônica da Represa Samambaia, Goiás, Brasil. Tese de Doutorado, Universidade de São Paulo.

Nogueira, I.S. \& Oliveira, J.E. 2009. Chlorococcales e Ulothricales de hábito colonial de quatro lagos artificiais do município de Goiânia, GO. Iheringia série Botânica 64: 123143. 
Pažoutová, M. 2008. Phylogenetic Diversity and Generic Concept in the Family Radiococcaceae, Chlorophyta. Tese de Doutorado, Univerzita Karlova v Praze.

Picelli-Vicentim, M.M. 1987. Chlorococcales planctônicas do Parque Regional do Iguaçu, Curitiba, Estado do Paraná. Revista Brasileira de Biologia 47: 57-85.

Ramos, G.J.P.; Bicudo, C.E.M.; Góes-Neto, A. \& Moura, C.W.N. 2012. Monoraphidium and Ankistrodesmus (Chlorophyceae, Chlorophyta) from Pantanal dos Marimbus, Chapada Diamantina, Bahia State, Brazil. Hoehnea 39(3): 421434.

Ramos, G.J.P.; Bicudo, C.E.M.; Góes-Neto, A. \& Moura, C.W.N. 2014. New additions of coccoid green algae to the phycoflora of Brazil and the Neotropics. Acta Botanica Brasilica 28(1): 8-16.

Rosini, E.F.; Sant'Anna, C.L. \& Tucci, A. 2012. Chlorococcales (exceto Scenedesmaceae) de pesqueiros da Região Metropolitana de São Paulo, SP, Brasil: levantamento florístico. Hoehnea 39(1): 11-38.

Rosini, E.F.; Sant'Anna, C.L. \& Tucci, A. 2013. Scenedesmaceae (Chlorococcales, Chlorophyceae) de pesqueiros da Região Metropolitana de São Paulo, SP, Brasil: levantamento florístico. Hoehnea 40(4): 661-678.

Sant'Anna, C.L. 1984. Chlorococcales (Chlorophyceae) do Estado de São Paulo, Brasil. J. Cramer. (Bibliotheca Phycologica 67), Berlin.

Sant'Anna, C.L. \& Martins, D.V. 1982. Chlorococcales (Chlorophyceae) dos lagos Cristalino e São Sebastião, Amazonas, Brasil: taxonomia e aspectos limnológicos. Revista Brasileira de Botânica 5: 67-82.

Severiano, J.S.; Moura, A.N.; Oliveira, H.S.B.; CordeiroAraújo, M.K. \& Dantas, E.W. 2012. Micro-phytoplankton richness in Contas river, state of Bahia, northeastern Brazil. Check List 8(2): 218-223.
Skuja, H. 1964. Grundzüge der Algenflora und Algenvegetation der Fjeldgegenden um Abisko in Schwedisch-Lappland. Nova Acta Societatis Scientiarum Upsaliensis 16(3): 1-404.

Smith, G.M. 1920. Phytoplankton of the inland lakes of Wisconsin, 1: Myxophyceae, Phaeophyceae, Heterokontae and Chlorophyceae. Bulletin of the Wisconsin Geological and Natural History Survey 57: 1-243.

Souza, D.B.S. \& Felisberto, S.A. 2014. Comasiella, Desmodesmus, Pectinodesmus e Scenedesmus na comunidade perifítica em ecossistema lêntico tropical, Brasil Central. Hoehnea 41(1): $109-120$.

Torgan, L.C. 1997. Estrutura e Dinâmica da Comunidade Fitoplanctônica na Laguna dos Patos, Rio Grande do Sul, Brasil, em um Ciclo Anual. Tese de Doutorado, Universidade Federal de São Carlos.

Torgan, L.C. \& Hentschke, G.S. 2011. Estrutura da comunidade de Chlorococcales 'sensu lato' (Chlorophyceae) em diferentes hábitats aquáticos e hidroperíodos. Acta Botanica Brasilica 25(1): 83-94.

Tsarenko, P.M. \& John, D.M. 2011. Phylum Chlorophyta (Green Algae) Order Sphaeropleales In: D.M. John, B.A. Whitton \& A.J. Brook (eds), The Freshwater Algal Flora of the British Isles. 2 Ed. Cambridge University Press, Cambridge, p. 461-465

Tucci, A.; Sant'Anna, C.L.; Gentil, R.C. \& Azevedo, MT.P. 2006. Fitoplâncton do Lago das Garças, São Paulo, Brasil: um reservatório urbano eutrófico. Hoehnea 33: 147-175.

Tucci, A.; Branco, C.Z.; Peres, C.K.; Fajar, A. \& Menezes, M. 2014a. Chlorophyceae. In: Lista de Espécies da Flora do Brasil. Jardim Botânico do Rio de Janeiro. Disponível em http://floradobrasil.jbrj.gov.br/jabot/floradobrasil/FB118453; acesso em 27 out. 2014.

Tucci, A.; Nogueira, I. \& Menezes, M. 2014b. Trebouxiophyceae. In: Lista de Espécies da Flora do Brasil. Jardim Botânico do Rio de Janeiro. Disponível em http://floradobrasil.jbrj.gov.br/ jabot/floradobrasil/FB118555; acesso em 2 jul. 2014. 